\title{
Examination of Air Pollution's Relationship with COVID-19, Physical and Mental Health
}

\author{
1 Hamdard College of Medicine, Karachi, Pakistan \\ 2 Cort Piil Helsesenter, Bergen, Norway \\ 3 Baqai Medical University, Karachi, Pakistan \\ ${ }^{4}$ Lehigh Valley Hospital, Allen Town, PA, USA \\ 5 Independent researcher, Waco, TX, USA
}

Hina Islam¹, Irfan Sharif Shakoori², Fauzia Aslam³ ${ }^{3}$ Gohar Ashraf ${ }^{4}$, Hammad Akram $^{5}$

\section{CORRESPONDENCE}

\section{Hammad Akram}

1201 S. Trl. Waco, TX, USA

E-mail: hammadakram77@yahoo.com

\section{ARTICLE HISTORY}

Received: July 30, 2020

Accepted: October 26, 2020
Hina Islam • Hamdard College of Medicine, Hub Chawki Link, Madinatul Hikmat Gadap Town, Karachi, Karachi City, Sindh, Pakistan. Tel: +92 2136440214 , E-mail: hina.islam@yahoo.com

Irfan Sharif Shakoori • Cort Piil-smauet 7, 5005 Bergen, Norway. Tel: +47 55236 010, E-mail: dr.sharif2108@gmail.com

Fauzia Aslam • 51, Deh Tor, Gadap Road, Near Toll Plaza, Super Highway P.O. Box 2407, 75340 Karachi, Pakistan. Tel: +92 2134410293 to 298, +92 2134410 427 to 430, E-mail: fauzia_aslam@yahoo.com

Gohar Ashraf • 1200 S Cedar Crest Blvd, Allentown, PA 18103, USA. Tel: +1 610402 8000, E-mail: goharashraf@gmail.com

\section{ABSTRACT}

Air pollution is a result of natural phenomena or human activities that can cause the release of harmful substances in the environment, leading to adverse health outcomes among living beings. Pollution is associated with adverse health impacts on multiple organ systems among humans. While the respiratory and cardiovascular systems are mainly affected, there are other health issues related to the eyes, skin, brain, blood, immunity, behavioral/mental well-being, and reproduction among exposed individuals. Air pollutants can especially have higher health impacts on people at the extremes of their ages (children and elderly) and on those suffering from underlying respiratory and heart issues. Pollutants such as ozone, sulfur dioxide, particulate matter, and nitrogen dioxide have respiratory effects among children and adults and are associated with increased respiratory diseases, asthma exacerbations, and related hospitalizations. Carbon monoxide interferes with transporting oxygen by forming carboxyhemoglobin leading to cardiovascular, neurological, and respiratory problems. Particulate matter is a heterogeneous mixture of tiny particles of varying compositions found in the atmosphere and has a wide variety of severe health effects. Particulate matter emits from combustion, diesel engines, power generation, and wood-burning, and certain industrial activities. Lead is considered neurotoxic and has more severe consequences among children. Here we summarize characteristics of six criteria air pollutants and associated air quality risk assessment parameters known as the Pollutant Standard Index (PSI). The present manuscript also examines the impact of air pollution on human behavior, mental well-being, and neurological health consequences, as air pollution has been associated with cognitive decline, hyperactivity, dementia, anxiety, depression, aggression, and Alzheimer's disease-related changes. Lastly, we also attempt to look into any relationship between air pollutants and Coronavirus disease (COVID-19) and examine its possible association with a higher COVID-19 incidence, complications, and mortality.

Keywords: particulate air pollution, adverse health effects, human health, COVID-19, environmental health, Pollutant Standard Index 


\section{BACKGROUND}

Air pollution is the presence of harmful substances due to natural phenomena or anthropogenic activities in the environment that can have detrimental health consequences on humans when exposed. ${ }^{1,2}$ Air pollution is categorized into outdoor (ambient) and indoor types. ${ }^{1,2}$ According to the World Health Organization (WHO), 9 out of 10 individuals are inhaling polluted air, which results in millions of deaths each year. ${ }^{2}$ Here we explore the impacts of air pollution on human behavior, mental well-being, and neurological health consequences while summarizing characteristics of six criteria air pollutants and associated parameters known as the Pollutant Standard Index (PSI). Furthermore, we also attempt to look into any relationship between air pollutants and Coronavirus disease (COVID-19).

\section{TYPES, MECHANISM, AND COMMON HEALTH IMPACTS}

There is already clear proof that both short- and long-term ambient air quality changes are correlated with elevated mortality and morbidity among adults and children. ${ }^{3,4} \mathrm{Six}$ air pollutants including carbon monoxide, sulfur dioxide, lead, particulate matter, ozone, and nitrogen oxides (nitric oxide and nitrogen dioxide) all are associated with adverse health occurrence among exposed individuals (Table 1). ${ }^{5-8}$ The PSI is a generally used risk assessment parameter derived from the ambient concentration of the major air pollutants. ${ }^{9}$ The PSI can be used to assess air pollution levels from 0 to 500, values above 100 being considered unhealthy. ${ }^{9}$

In household settings or indoors, air pollution is associated with fuel combustion (appliances, heating, stove etc.), tobacco use, building materials, household cleaning chemicals, heating/cooling systems, and pesticides. ${ }^{10}$ Inadequate ventilation or movement of outdoor pollutants into indoor spaces can further deteriorate air quality. ${ }^{10} \mathrm{In}$ door (household) pollution has been linked to higher lung cancer risk, especially when houses are not well ventilated, coal is used for household activities, and the residence is located near industrial areas. ${ }^{11-13}$ In outdoor settings, the pollutants can negatively influence cardiovascular, neurological, and respiratory health. Particulate matter (PM), which is a complex mixture of diverse particles (sulfate, ammonia, carbon, mineral dust, nitrate compounds), has been associated with morbidity and mortality related to respiratory and cardiovascular illness. ${ }^{14,15}$ Sulfur dioxide and ozone both act as respiratory irritants and can trigger or deteriorate asthma and other respiratory conditions. ${ }^{15,16}$
Nitrogen dioxide has also been associated with respiratory conditions such as asthma, bronchitis, increased susceptibility of lung infections, and wheezing. ${ }^{15,17}$ Lead exists naturally or through the burning of fossil fuel, industries, and mining, and it is associated with neurological and renal problems amongst exposed individuals. Children are more vulnerable to the effects of lead. ${ }^{2}$ It is evident from studies that air pollution has negative impacts on infants' and children's health and is linked with preterm birth, lung developmental/functional issues, and overall increased morbidity and mortality. ${ }^{18-21}$ Since the lung tissue is still in development and over $80 \%$ of alveolar growth occurs after birth, infants are more susceptible to air pollution and environmental toxins. ${ }^{22-24}$ In time-series studies conducted in cities with notoriously high levels of pollution, such as Mexico City, Seoul, and Sao Paulo, associations between particulate matter $\leq 10 \mu \mathrm{m}$ (PM10) and infant mortality have been found. ${ }^{25-27}$ Spatial similarities within the Czech Republic and the US have been reported between postneonatal mortality and atmospheric particulate matter. ${ }^{28,29}$

\section{HUMAN BEHAVIOR, MENTAL HEALTH, AND NEUROLOGICAL DISORDERS}

The effect of noise, heat, and air pollution on human behavior, specifically aggression, has been documented. Although the respiratory and cardiovascular impacts of air pollution are well known, recent research shows that it also contributes to behavioral, psychological, and neurological issues. The mechanism of this is not precise. However, tiny pollution particles can reach the brain directly from nasal passages. ${ }^{30,31}$ Furthermore, particles can also reach the brain after being absorbed in the blood through the alveoli. ${ }^{31}$ Once these pollution particles reach the brain cells, they induce an inflammatory response that could lead to neurodegeneration. ${ }^{31}$ The consequences of high and long-term exposure are seen in forms of cognitive decline, especially among children, causing hyperactivity, dementia, anxiety, depression, aggression, and can even predispose to Alzheimer's disease. ${ }^{30,31}$ In one Chinese study, a high level of air pollution was associated with an increase in sedentary behavior, leading to other health issues. ${ }^{32}$ In a UK-based study, reduced indoor and outdoor air quality significantly affected emotional and behavioral problems related to conduct/temper and hyperactivity among children. ${ }^{33}$ Similar outcomes were noticed in a Californian study in which long-term exposure of PM2.5 possibly increased delinquent behavior among adolescents and teenagers. ${ }^{34}$ Exposure to lead is known to cause harmful effects on the nervous tissue. Studies have shown that not 
TABLE 1. Six criteria air pollutants

\begin{tabular}{|c|c|c|c|}
\hline & Source & Characteristics & $\begin{array}{l}\text { Health impacts } \\
\text { (e.g. on organ systems) }\end{array}$ \\
\hline Carbon Monoxide (CO) & $\begin{array}{l}\text { outdoor (vehicles, burning fossil } \\
\text { fuel), indoor air (gas heaters, stove, } \\
\text { furnaces) }\end{array}$ & no odor, color, taste or irritation & $\begin{array}{l}\text { cardiovascular, neurological, } \\
\text { respiratory }\end{array}$ \\
\hline Lead $(\mathrm{Pb})$ & $\begin{array}{l}\text { earth crust, burning fuel, mining, } \\
\text { industries }\end{array}$ & bluish grey metal & $\begin{array}{l}\text { neurological, renal, probable } \\
\text { carcinogen }\end{array}$ \\
\hline Nitrogen Oxides $\left(\mathrm{NO} \& \mathrm{NO}_{2}\right)$ & $\begin{array}{l}\text { motor emission, burning of oil or } \\
\text { coal, industries }\end{array}$ & non-flammable, colorless to brown & respiratory \\
\hline Ozone $\left(\mathrm{O}_{3}\right)$ & $\begin{array}{l}\text { motor emission, industries (boilers, } \\
\text { chemicals) }\end{array}$ & main ingredient in smog & $\begin{array}{l}\text { benefits: stratospheric ozone } \\
\text { protects from UV radiation, } \\
\text { harmful (ground level): respiratory }\end{array}$ \\
\hline Sulfur Dioxide $\left(\mathrm{SO}_{2}\right)$ & $\begin{array}{l}\text { coal and oil burning, volcanic } \\
\text { eruptions }\end{array}$ & colorless, pungent & respiratory \\
\hline Particulate Matter (PM) & $\begin{array}{l}\text { chemical reactions between } \\
\text { pollutants }\end{array}$ & $\begin{array}{l}\text { mixture of solid and liquid particles, } \\
\text { PM10: diameter } \leq 10 \mu \mathrm{m}, \mathrm{PM} 2.5 \text { : } \\
\text { diameter } \leq 2.5 \mu \mathrm{m} \text { (both PM10 and } \\
\text { PM2.5 are inhalable) }\end{array}$ & respiratory, heart \\
\hline
\end{tabular}

only lead is associated with a decline in cognition, intellect, and memory among children and adolescents, but if exposure occurs at a young age and continuously, it can result in personality and behavioral issues in adulthood. ${ }^{35,36}$ The literature also suggests lead exposure involvement in Parkinson's disease. ${ }^{37}$ As per some research studies, smoking, which contributes to environmental air pollution, can increase the risk of Parkinson's, although other studies state the opposite. ${ }^{37}$ Also, both active and passive smoking is linked with the etiology of multiple sclerosis. ${ }^{38}$

\section{AIR POLLUTION AND COVID-19}

As mentioned earlier, the long-term exposure to pollution has been connected to morbidity and mortality associated with respiratory inflammation, chronic lung disease, asthma, and cardiovascular disorders. A study examining data from over 3,000 US counties shows that in areas with slightly higher levels of PM2.5 (i.e., $1 \mu \mathrm{g} / \mathrm{m}^{3}$ ), there was an $8 \%$ increase in COVID-19-related deaths. ${ }^{39}$ Historically, this kind of relationship was also seen in a 2003 Chinese study where both short- and long-term exposure to air pollution was positively associated with severe acute respiratory syndrome (SARS)-related mortality. ${ }^{40}$ Air pollution can also increase the incidence of COVID-19 as examined in a recent Chinese study where short-term exposure to $\mathrm{O}_{3}, \mathrm{PM}(2.5 \& 10)$, and $\mathrm{NO}_{2}$ was significantly associated with higher numbers of COVID-19 cases. ${ }^{41}$ Further studies are needed to explore the role of the PSI or air pollution indices, individual and combined effects of air pollutants on COVID-19 incidence, disease course, and mortality. Hypothesis testing based on the dose-response relation- ships, temporal trends, exposure inequality by geography, and monthly/yearly variation of air pollution on COVID-19 could provide crucial information about the dynamics and management of COVID-19 infection. More studies are needed to examine the interrelationship between the COVID-19 disease process and air pollutants. To examine this vital relationship, diverse and enhanced surveillance approaches coupled with multidisciplinary and mixedmethod research studies can be crucial. ${ }^{42,43}$

\section{SUMMARY \& CONCLUSIONS}

Environmental toxins and hazards have adverse impacts on humans throughout their lifespan. For instance, exposures during pregnancy can result in developmental issues, birth defects, intellectual delays, and cancers. After birth, while growing, they are more susceptible to air pollution and other toxins as their organs are still in developmental phases. Although all age groups are vulnerable to the effects of air pollution, the impacts are higher among people of extreme ages. The present short review examines the impact of air pollutants on humans and particularly explores associated mental health outcomes. The persistent exposure of pollutants can cause impairment of different organ systems. We also see that mortality is higher in places where air pollution is a significant issue. Furthermore, early studies are showing unfavorable COVID-19-related outcomes in the presence of high levels of air pollutants. More research is needed to examine the interrelationship between the COVID-19 disease process and air pollutants, with the use of multidisciplinary research studies. Rapid industrialization, increased use of cars, buses, and airplanes during the last 
and current centuries have contributed to public health issues related to air pollution. It is known that the use of motor vehicles can contribute largely to the pollution in a geographical area; hence, changes in transportation mode (e.g., reduced use of cars, increased use of bicycles, electric vehicles, or mass public transportation etc.) can help in reducing this problem. City planning, opportunities to provide easy access to the public transportation systems, increase in vegetation, and plantation of trees can also contribute.

\section{CONFLICT OF INTEREST}

None declared.

\section{REFERENCES}

1. National Institute of Environmental Health Sciences. Air Pollution and You Health. https://www.niehs.nih.gov/health/topics/agents/air-pollution/index. $\mathrm{cfm}$

2. World Health Organization. Air pollution.https://www.who.int/health-topics/ air-pollution\#tab=tab_1

3. Bobak M, Leon DA. The effect of air pollution on infant mortality appears specific for respiratory causes in the postneonatal period. Epidemiology. 1999;10:666-70

4. Hajat S, Armstrong B, Wilkinson P, Busby A, Dolk H. Outdoor air pollution and infant mortality: analysis of daily time-series data in 10 English cities. Journal of Epidemiology \& Community Health. 2007;61:719-722.

5. Centers for Disease Control and Prevention. Air Quality, Air Pollutants. https://www.cdc.gov/air/pollutants.htm

6. United States Environmental Protection Agency. Carbon Monoxide (CO) Pollution in Outdoor Air. https://www.epa.gov/co-pollution/basicinformation-about-carbon-monoxide-co-outdoor-air-pollution\#What\%20 is $\% 20 \mathrm{CO}$

7. United States Environmental Protection Agency. Ground-level Ozone Pollution. https://www.epa.gov/ground-level-ozone-pollution

8. United States Environmental Protection Agency. Particulate Matter (PM) Pollution. https://www.epa.gov/pm-pollution/particulate-matter-pm-basics \#PM

9. U. S. Environmental Protection Agency. Pollutant Standard Index (PSI). https://www3.epa.gov/ttnamti1/archive/psi.html

10. United States Environmental Protection Agency. Indoor Air Quality (IAQ). https://www.epa.gov/indoor-air-quality-iaq/introduction-indoor-air-quality

11. Akram H, Ashraf G. Commentary: Second-hand smoke and other potential lung cancer exposures among non-smoking women. International Journal of Medical Sciences and Technology. 2017;7:25

12. Kim C, Gao YT, Xiang YB, et al. Home kitchen ventilation, cooking fuels, and lung cancer risk in a prospective cohort of never smoking women in Shanghai, China. Int J Cancer. 2015:136:632-638.

13. Ko YC, Lee $\mathrm{CH}$, Chen MJ, et al. Risk factors for primary lung cancer among non-smoking women in Taiwan. Int J Epidemiol. 1997:26:24-31.

14. World Health Organization. Ambient (outdoor) air pollution. https://www.who. int/news-room/fact-sheets/detail/ambient-(outdoor)-air-quality-and-health

15. Davidson $\mathrm{Cl}$, Phalen RF, Solomon PA. Airborne particulate matter and human health: a review. Aerosol Science and Technology. 2005;39:737749

16. EPA. Indoor Air Quality (IAQ). Ozone Generators that are Sold as Air Cleaners. https://www.epa.gov/indoor-air-quality-iaq/ozone-generatorsare-sold-air-cleaners\#: : :text=When\%20inhaled\%2C\%20ozone\%20 can\%20damage,body\%20to\%20fight\%20respiratory\%20infections
17. Nitschke M. Respiratory health effects of nitrogen dioxide exposure and current guidelines. International Journal of Environmental Health Research. 1999:9:39-53

18. Committee of the Environmental and Occupational Health Assembly of the American Thoracic Society. Health effects of outdoor air pollution. Am J Respir Crit Care Med. 1996;153:3-50

19. Committee of the Environmental and Occupational Health Assembly of the American Thoracic Society. Health effects of outdoor air pollution. Part 2. Am J Respir Crit Care Med. 1996:153:477-498.

20. Kim JJ. Ambient air pollution: health hazards to children. Pediatrics 2004;114:1699-1707

21. Schwartz J. Air pollution and children's health. Pediatrics. 2004;113:1037 1043 .

22. Dietert RR, Etzel RA, Chen D, et al. Workshop to identify critical windows of exposure for children's health: immune and respiratory systems work group summary. Environ Health Perspect. 2000;108:483-490.

23. Plopper CG. Fanucchi MV. Do urban environmental pollutants exacerbate childhood lung diseases? Environ Health Perspect. 2000;108:A252-A253.

24. Pinkerton KE, Joad JP. The mammalian respiratory system and critica windows of exposure for children's health. Environmental Health Perspectives. 2000;108:457-462.

25. Loomis D, Castillejos M, Gold DR, McDonnell W, Borja-Aburto VH. Air pollution and infant mortality in Mexico City. Epidemiology. 1999:118-123.

26. Ha EH, Lee JT, Kim H, et al. Infant susceptibility of mortality to air pollution in Seoul, South Korea. Pediatrics. 2003:111:284-290.

27. Lin CA, Pereira LA, Nishioka DC, Conceição GM, Braga AL, Saldiva PH. Air pollution and neonatal deaths in Sao Paulo, Brazil. Brazilian Journal of Medical and Biological Research. 2004;37:765-770.

28. Bobak M, Leon DA. Air pollution and infant mortality in the Czech Republic 1986-88. The Lancet. 1992:340:1010-1014

29. Woodruff TJ, Grillo J, Schoendorf KC. The relationship between selected causes of postneonatal infant mortality and particulate air pollution in the United States. Environmental Health Perspectives. 1997;105:608-612.

30. Peeples L. News Feature: How air pollution threatens brain health Proceedings of the National Academy of Sciences. 2020;17:13856-13860

31. Weir K. Smog in our brains. Monitor on Psychology. 2012:43:32

32. Yu H, Cheng J, Gordon SP, et al. Impact of Air Pollution on Sedentary Behavior: A Cohort Study of Freshmen at a University in Beijing, China. Int J Environ Res Public Health. 2018;15:2811.

33. Midouhas E, Kokosi T, Flouri E. The quality of air outside and inside the home: associations with emotional and behavioural problem scores in early childhood. BMC Public Health. 2019;19:406.

34. Younan D, Tuvblad C, Franklin M, et al. Longitudinal analysis of particulate air pollutants and adolescent delinquent behavior in Southern California. Journal of Abnormal Child Psychology. 2018;46:1283-1293.

35. Williams JH, Ross L. Consequences of prenatal toxin exposure for mental health in children and adolescents. European Child \& Adolescent Psychiatry. 2007:16:243-253.

36. Reuben A, Schaefer JD, Moffitt TE, et al. Association of Childhood Lead Exposure With Adult Personality Traits and Lifelong Mental Health. JAMA Psychiatry. 2019;76:418-425

37. Elbaz A, Moisan F. Update in the epidemiology of Parkinson's disease. Current Opinion in Neurology. 2008;21:454-460.

38. Lauer K. Environmental risk factors in multiple sclerosis. Expert Review of Neurotherapeutics. 2010;10:421-440.

39. Wu X, Nethery RC, Sabath BM, Braun D, Dominici F. Exposure to air pollution and COVID-19 mortality in the United States. medRxiv. 2020 Jan 1.

40. Cui Y, Zhang ZF, Froines J, et al. Air pollution and case fatality of SARS in the People's Republic of China: an ecologic study. Environmental Health. 2003:2:1-5.

41. Zhu Y, Xie J, Huang F, Cao L. Association between short-term exposure to air pollution and COVID-19 infection: Evidence from China. Sci Tota Environ. 2020:727:138704

42. Aslam F, Akram H. Mixed-Methodology in Disease Surveillance, Response, and Control. Int J Basic Sci Med. 2019:2:43-44.

43. Akram H. Enhancing Public Health Capacity by using Epidemiological Teams in a Public Health Setting. Cureus. 2017:9:e1381. 